\title{
Phase Separation and Viscoelastic Behavior of Semicompatible Polymer Blends: Poly(vinylidene fluoride)/ Poly(methyl methacrylate) System
}

\author{
Yasushi HIRATA ${ }^{\dagger}$ and Tadao KotAKA* \\ Department of Macromolecular Science, Osaka University, \\ Toyonaka, Osaka 560, Japan
}

(Received September 3, 1980)

\begin{abstract}
Thermal and dynamic mechanical analyses of variously processed blends of poly(vinylidene fluoride) $\left(\mathrm{PVF}_{2}\right)$ and poly(methyl methacrylate) (PMMA) were carried out to elucidate the effects of lower-critical-solution-temperature (LCST) behavior reported earlier by Paul on the morphologies and properties of this system. The two components are miscible in the blends with $\mathrm{PVF}_{2}$ content $\phi_{\mathrm{w}}<0.6$. Such blends exhibit single glass transition at $T_{\mathrm{g}}$ 's, which follow the Gordon-Taylor scheme. On the other hand, the blends with $\phi_{\mathrm{w}}>0.6$, prepared by melt-mixing and annealing at $200^{\circ} \mathrm{C}$ for a sufficiently long period of time, exhibit two $T_{\mathrm{g}}$ 's and two $T_{\mathrm{m}}$ 's, implying a four-phase morphology. In such blends an LCST-type phase separation has taken place at a temperature as low as $200^{\circ} \mathrm{C}$ to give an amorphous mixture with $\phi_{\mathrm{w}} \cong 0.6$ and a nearly pure $\mathrm{PVF}_{2}$ melt. Quenching of such melts leads to a four-phase morphology composed of a mixed amorphous phase with $T_{\mathrm{g}} \cong 55^{\circ} \mathrm{C}$, an imperfect crystalline phase grown out from the mixture and hence having a low $T_{\mathrm{m}}$, and a nearly pure semicrystalline $\mathrm{PVF}_{2}$ domains similar to form II crystals with $T_{\mathrm{g}} \cong-40^{\circ} \mathrm{C}$ and a higher $T_{\mathrm{m}}$.

KEY WORDS Amorphous Polymer-Crystalline Polymer Blends / Semicompatible Polymer Blend / Poly(vinylidene fluoride) / Poly(methyl methacrylate) / Phase Separation / Differential Scanning Calorimetry / Viscoelastic Properties / Melt-Mixed Blend / Solution-Mixed Blend /
\end{abstract}

Polymer blends of poly(vinylidene fluoride) $\left(\mathrm{PVF}_{2}\right)$ and poly(methyl methacrylate) (PMMA) have been the subject of several recent studies. ${ }^{1-9}$ The general conclusion is that these components are miscible in the amorphous state, i.e., above the melting point of $\mathrm{PVF}_{2}\left(T_{\mathrm{m}} \cong 170^{\circ} \mathrm{C}\right)$. Below $T_{\mathrm{m}}$ the $\mathrm{PVF}_{2}$ crystallizes from the melt, especially with high $\mathrm{PVF}_{2}$ content, $\phi_{\mathrm{w}}$, if the blend is kept above its glass-transition temperature, $T_{\mathrm{g}}$. The blend forms a two-phase system consisting of a $\mathrm{PVF}_{2}$ crystalline phase and a mixed amorphous phase. In short, this system is a typical example of a semicompatible polymer blend composed of a semicrystalline polymer and an amorphous polymer, in which phase

$\dagger$ Present address: Research and Development Department, Bridgestone Tire Co., 2800-1 Ogawahigashimachi, Kodaira 187, Japan.

* To whom correspondence should be addressed. separation occurs only by crystallization of the former. However, Paul et al. ${ }^{6}$ pointed out that this system exhibits lower-critical-solution-temperature (LCST) behavior with cloud points, $T_{\mathrm{p}}$, in a temperature range of about $330^{\circ} \mathrm{C}$ for blends with high $\phi_{\mathrm{w}}$. The $T_{\mathrm{p}}$ are far above the ceiling temperature for PMMA $\left(T_{\mathrm{d}} \cong 220^{\circ} \mathrm{C}\right)$. Such an LCST behavior, if it really exists, might bring about additional complications to the phase-separation behavior and physical properties of $\mathrm{PVF}_{2} / \mathrm{PMMA}$ blends. If fact, there are certain discrepancies between reported $T_{\mathrm{g}}$ versus composition data for melt-mixed blends ${ }^{2,5}$ and for solvent-cast blends ${ }^{3}$ of this system. Thus, we have attempted to resolve these problems by comparing the thermal and dynamic mechanical behavior of melt blends with that of solvent-cast blends of this system. The results obtained are reported in this paper. 


\section{EXPERIMENTAL}

\section{Materials}

The $\mathrm{PVF}_{2}$ used in this study was a powder-form sample (KF Polymer 1100) purchased from Kureha Kasei Co., while three PMMA samples were prepared at our laboratory by a radicalpolymerization method with azobis-isobutylonitrile as the initiator. For purification of the samples, the $\mathrm{PVF}_{2}$ was dissolved in hot acetone and precipitated in excess water, while the PMMA samples were dissolved in benzene and precipitated in excess methanol. For each sample the procedure was repeated twice. Molecular weights and the distributions of the PMMA samples were determined on a gel-permeation chromatograph (GPC: Toyo Soda Mfg. Co., Model HCL-801A) with tetrahydrofuran (THF) as carrier. Characterization data ${ }^{10}$ are given in Table I.

\section{Preparation of Blends}

(a) Melt-Mixed Blends. The $\mathrm{PVF}_{2}$ and PMMA samples were mixed and kneaded in a mortar with a small amount of water to form a paste. This paste was dried, hot-pressed into films at $200^{\circ} \mathrm{C}$ for 20 minutes, and then quenched in liquid $\mathrm{N}_{2}$. The film was then cut into pieces, which were remelted and hot pressed at $200^{\circ} \mathrm{C}$ for 20 minutes, and quenched in liquid $\mathrm{N}_{2}$. To obtain well-mixed, homogeneous specimens for the later measurements, we repeated the melting-quenching process at least 15 times, since a preliminary test on a $\mathrm{PVF}_{2} / \mathrm{PMMA}$ III ( $50 / 50$ by weight) blend indicated that the degree of crystallinity, the $T_{\mathrm{g}}$, the $T_{\mathrm{m}}$, and other thermal and mechanical properties of the blend appoached to constant values only after repeating this procedure at least from 10 to 20 times. These specimens were coded as melt-quenched (MQ) blends. Some of the MQ blends were further annealed at a desired temperature, $t^{\circ} \mathrm{C}$, controlled within $\pm 1^{\circ} \mathrm{C}$ for 16 hours. They were coded as melt-annealed $\left[\mathrm{MA}\left(t^{\circ} \mathrm{C}\right)\right]$ blends.

(b) Solution-Mixed Blends. Films were prepared by casting from $3 \% N, N$-diemthylformamide (DMF) solutions according to the method described by Nishi and Wang. ${ }^{3}$ The as-cast films were coded as solvent-cast (S) blends. Again, some of these films were heat-treated at $200^{\circ} \mathrm{C}$ in a hot-press for a certain period of time $(t \mathrm{~min})$, and then quenched in liquid $\mathrm{N}_{2}$. The films were coded as solvent-castmelt-quenched [SM( $t \min ) \mathrm{Q}]$ blends.

\section{Methods}

The dynamic mechanical measurements were made with a Rheovibron Model DDV-II dynamic viscoelastometer (Toyo-Baldwin Co., Tokyo) at a heating rate of about $1^{\circ} \mathrm{C} \mathrm{min}{ }^{-1}$. The frequency was $110 \mathrm{~Hz}$ and the temperature range was from $-120^{\circ} \mathrm{C}$ to $170^{\circ} \mathrm{C}$. For the calorimetric study a Rigaku Denki (Tokyo) Model YDSM differential scanning calorimeter was used at a heating rate of $10^{\circ} \mathrm{C} \mathrm{min}^{-1}$ in the range from $-70^{\circ} \mathrm{C}$ to $220^{\circ} \mathrm{C}$.

\section{RESULTS}

\section{Behavior of Melt-Mixed Blends}

The data given in this and in the following sections were obtained on $\mathrm{PVF}_{2}-\mathrm{PMMA}$ II blends, unless otherwise specified.

(a) Thermal Behavior. Figure 1 shows several

Table I. Homopolymer characterization data

\begin{tabular}{|c|c|c|c|c|}
\hline Sample & $M_{n} \times 10^{-4}$ & $M_{w} \times 10^{-4}$ & $M_{w} / M_{n}$ & Source $^{\mathrm{a}}$ \\
\hline $\mathrm{PVF}_{2}$ & $7^{\mathrm{b}}$ & - & - & Kureha KF polymer 1100 \\
\hline PMMA I & 5.9 & 10 & 1.7 & $\begin{array}{l}\text { Solution polymerization in toluene at } 58^{\circ} \mathrm{C} \text { for } 4.5 \mathrm{~h} \text {. } \\
{[\mathrm{I}]=7,[\mathrm{M}]=80}\end{array}$ \\
\hline PMMA II & 12 & 30 & 2.5 & $\begin{array}{l}\text { Bulk polymerization at } 90^{\circ} \mathrm{C} \text { for } 1 \mathrm{~h} \text {. } \\
{[\mathrm{I}]=0.5}\end{array}$ \\
\hline PMMA III & 200 & 340 & 1.7 & $\begin{array}{l}\text { Bulk polymerization at } 58^{\circ} \mathrm{C} \text { for } 1 \mathrm{~h} \text {. } \\
{[\mathrm{I}]=2.5 \times 10^{-3}}\end{array}$ \\
\hline
\end{tabular}

${ }^{\text {a }}$ [I], AIBN mol $\%$; [M], MMA mol\%.

b From Manufacturer's catalogue. Data for PMMAs were obtained by GPC with THF carrier. 


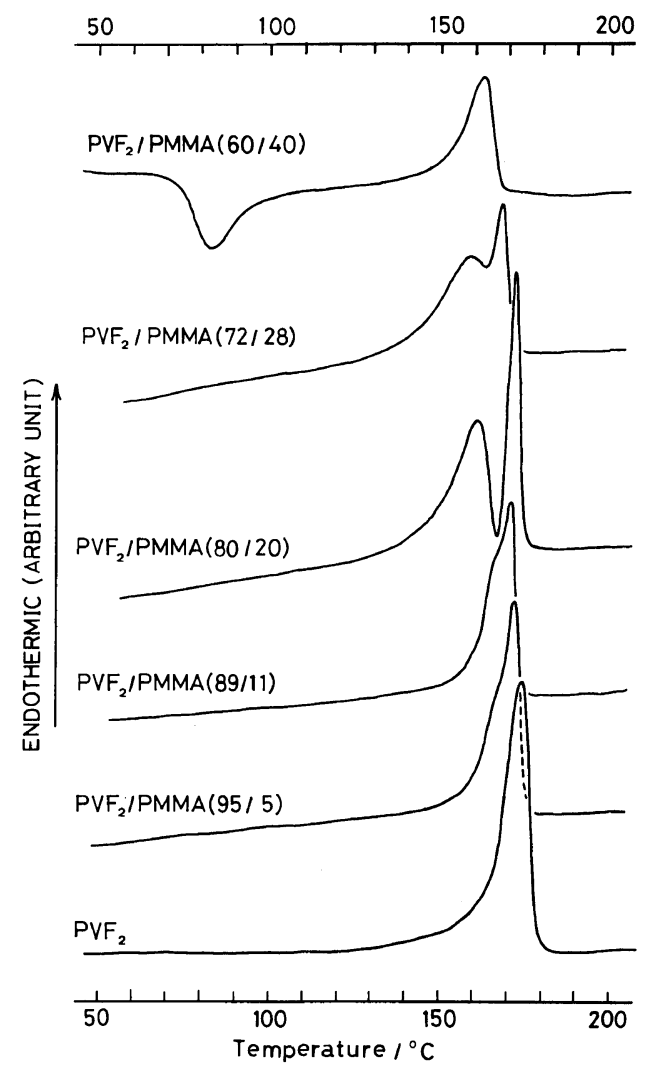

Figure 1. DSC thermograms for crystallization and melting of $\mathrm{PVF}_{2}$ in $\mathrm{PVF}_{2} / \mathrm{PMMA}$ II (MQ) blends with high content $\phi_{\mathrm{w}}>0.6$, obtained at a heating rate of $10^{\circ} \mathrm{C}$ $\min ^{-1}$.

examples of the differential scanning calorimetry (DSC) thermograms for crystallization and melting of $\mathrm{PVF}_{2}$ in $\mathrm{PVF}_{2} / \mathrm{PMMA}$ II (MQ) blends with high $\mathrm{PVF}_{2}$ content, $\phi_{\mathrm{w}}$ (by weight). For those with $\phi_{\mathrm{w}}<0.6$ neither crystallization nor melting peaks were observed, implying that the two components are in the amorphous state and presumably mixed with each other. However, for MQ (60/40) blend, both exothermic crystallization and endothermic melting peaks were observed, indicating that crystallization of $\mathrm{PVF}_{2}$ took place during the DSC measurement. Interestingly, for the MQ (72/28) and $(80 / 20)$ blends, we observe no crystallization peaks but two melting peaks. Presumably, in the MQ (72/28) and (80/20) blends, crystallization of $\mathrm{PVF}_{2}$ proceeded rapidly almost to the completion during the quenching process. The two peaks merged into an endothermic peak with a small

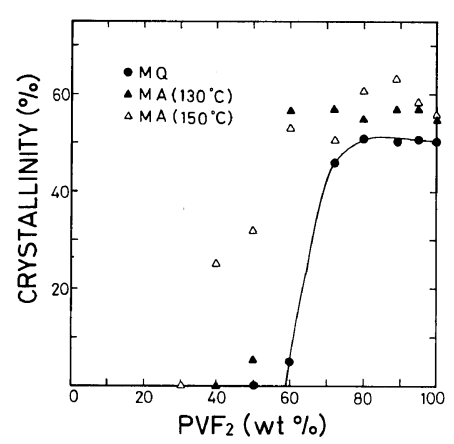

Figure 2. Dependence of degree of crystallinity, $X_{\mathrm{c}}$, of $\mathrm{PVF}_{2}$ on weight percent of $\mathrm{PVF}_{2}, \phi_{\mathrm{w}}$, in melt-mixed blend as determined by DSC.

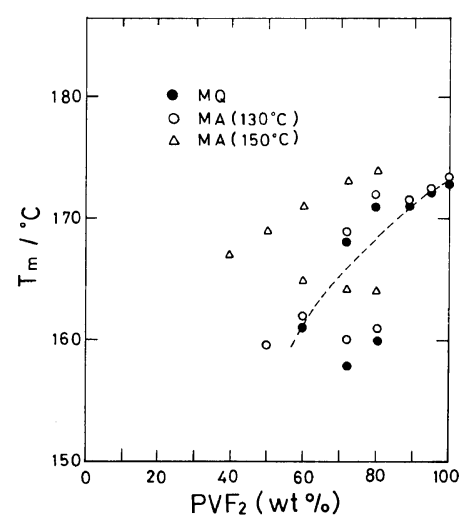

Figure 3. Dependence of melting point, $T_{\mathrm{m}}$, of $\mathrm{PVF}_{2}$ crystals on weight percent of $\mathrm{PVF}_{2}, \phi_{\mathrm{w}}$, in melt-mixed blends as determined by DSC.

shoulder and finally into a single peak of pure $\mathrm{PVF}_{2}$ as $\phi_{\mathrm{w}}$ underwent a further increase. Apparently these two peaks imply the presence of two different crystals.

Annealing of MQ blends at an adequate temperature, $T_{\mathrm{c}}$, below the $T_{\mathrm{m}}$ resulted in the formation of $\mathrm{PVF}_{2}$ crystals. For MA blends with $\phi_{\mathrm{w}}$ as low as 0.4 crystallization and melting peaks became observable, and also for MA blends with $\phi_{\mathrm{w}}>0.4$ the area under the melting peaks grew larger than that of the corresponding MQ blends. Figures 2 and 3 show, respectively, the $\phi_{\mathrm{w}}$ dependence of the degree of crystallinity, $X_{\mathrm{c}}$, and that of the peak temperatures, $T_{\mathrm{m}}$, for melting of $\mathrm{PVF}_{2}$ crystals in the MQ and MA $\left(t^{\circ} \mathrm{C}\right)$ blends. The values of $X_{\mathrm{c}}$ are ratios of the specific enthalpies of fusion of $\mathrm{PVF}_{2}$ in the blend and in the homopolymer $\left(\cong 18 \mathrm{cal} \mathrm{g}^{-1}\right){ }^{11}$ For 


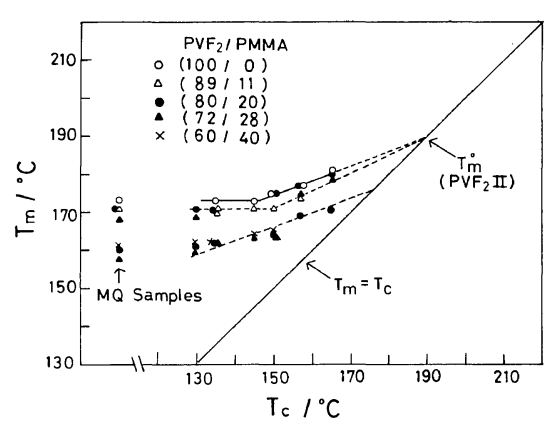

Figure 4. Plots of the melting point, $T_{\mathrm{m}}$, of $\mathrm{PVF}_{2}$ crystals in the melt-mixed blends versus the crystallization (annealing) temperature, $T_{\mathrm{c}}$.

blends with $0.7 \lesssim \phi_{\mathrm{w}} \lesssim 0.82$, the two $T_{\mathrm{m}}$ 's are plotted. For all these melt-mixed MQ and MA blends, we observe melting-point depressions roughly comparable to those in Nishi and Wang's results, which are shown in Figure 3 by a dashed curve. However, on examining these data more closely, we notice that the lower $T_{\mathrm{m}}$ 's are nearly equal to those of the blends with $\phi_{\mathrm{w}} \cong 0.6$, whereas the depression in the higher $T_{\mathrm{m}}$ 's is somewhat less than that demonstrated by Nishi and Wang ${ }^{3}$ for their solution-cast blends. This result might imply that a nearly pure $\mathrm{PVF}_{2}$ phase still contains a small amount of PMMA, or this behavior might be a mere artifact due to a kinetic effect during the crystallization process.

Figure 4 shows the effect of the annealing temperature $T_{\mathrm{c}}$ on observed melting temperatures, $T_{\mathrm{m}}$, for $\mathrm{PVF}_{2}$ and several MA blends. In the range of $T_{\mathrm{c}}$ below $145^{\circ} \mathrm{C}$, the $T_{\mathrm{m}}$ is nearly independent of $T_{\mathrm{c}}$ and is similar to that of the corresponding MQ blend. However, in the range of $T_{\mathrm{c}}$ above $145^{\circ} \mathrm{C}$, the $T_{\mathrm{m}}$ 's show a linear dependence on $T_{\mathrm{c}}$. The $T_{\mathrm{m}}$ corresponding to the higher temperature peak extrapolates to the equilibrium melting point $T_{\mathrm{m}}{ }^{\circ}$ $\left(\simeq 188^{\circ} \mathrm{C}\right)$ of form II $\mathrm{PVF}_{2}$ crystals, ${ }^{11}$ whereas that of the lower temperature peak converges to a value $\left(\simeq 178^{\circ} \mathrm{C}\right.$ ) which is about $10^{\circ} \mathrm{C}$ lower than the $T_{\mathrm{m}}^{\circ}$. Nishi and Wang ${ }^{3}$ also reported similar behavior in which the values extrapolated from the $T_{\mathrm{m}}$ 's of their solvent-cast blends are somewhat lower than that of pure $\mathrm{PVF}_{2}$, e.g., $8.6^{\circ} \mathrm{C}$ for $(50 / 50)$ blend and $4.0^{\circ} \mathrm{C}$ for $(82.5 / 17.5)$ blend. ${ }^{3}$ The $\mathrm{PVF}_{2}$ crystals in their solvent-cast blends are presumably in equilibrium, or more precisely, in a quasiequilibrium state with the amorphous mixture, and hence are different from form II crystals. In our experiments the

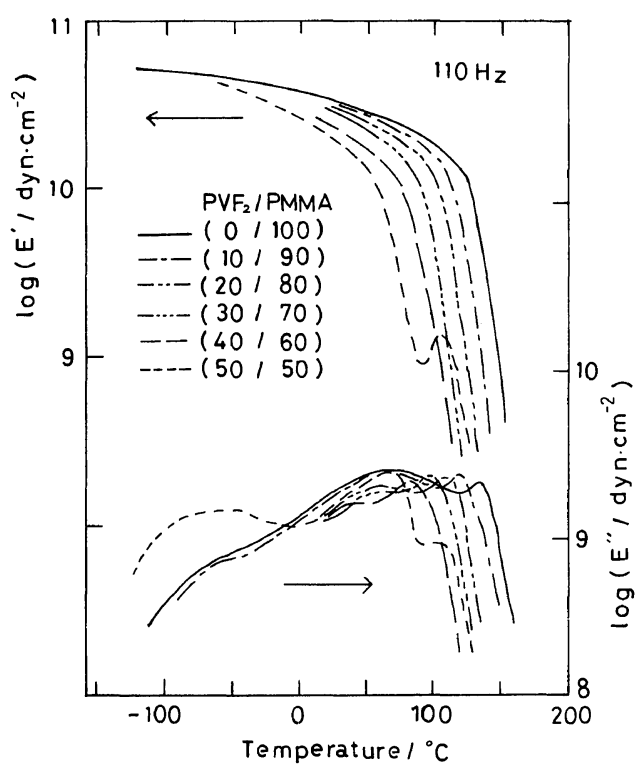

Figure 5. Dependence of dynamic storage, $E^{\prime}$, and loss, $E^{\prime \prime}$, moduli observed at the frequency of $110 \mathrm{~Hz}$ for amorphous MQ blends with the $\mathrm{PVF}_{2}$ content, $\phi_{\mathrm{w}} \leqq 0.5$.

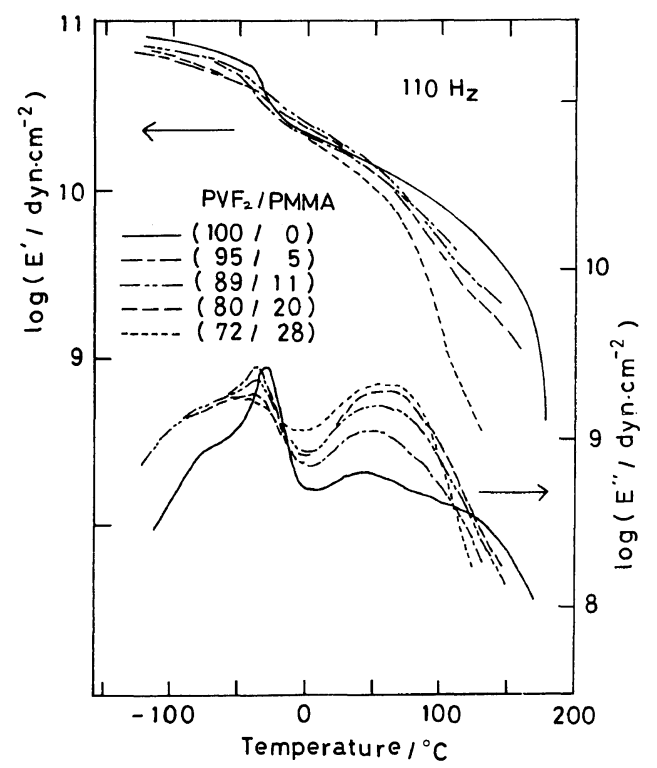

Figure 6. Temperature dependence of dynamic storage, $E^{\prime}$, and loss, $E^{\prime \prime}$, moduli at $110 \mathrm{~Hz}$ for semicrystalline MQ blends with $\phi_{\mathrm{w}}>0.70$.

crystals with the lower peak temperature are presumably equivalent to the crystals of their solvent-cast blends and might possibly have resulted 
from the amorphous mixture with $\phi_{\mathrm{w}} \cong 0.6$, whereas those having the higher peak temperatures are grown from the nearly pure amorphous $\mathrm{PVF}_{2}$ phase.

(b) Viscoelastic behavior. Figures 5 and 6 show plots of the dynamic storage modulus, $E^{\prime}$, and the dynamic loss modulus, $E^{\prime \prime}$, versus temperature (observed at a frequency of $110 \mathrm{~Hz}$ ) for PMMA II and $\mathrm{PVF}_{2} / \mathrm{PMMA}$ II MQ blends with $\phi_{\mathrm{w}} \leqslant 0.5$ and for those with $\phi_{\mathrm{w}}>0.7$ and $\mathrm{PVF}_{2}$, respectively. For the former series the temperature, at which a sharp decrease in $\log E^{\prime}$ and a peak in $\log E^{\prime \prime}$ occur, gradually shifts from the glass transition, $T_{\mathrm{g}}^{\text {PMMA }}$ ( $\simeq 131^{\circ} \mathrm{C}$ in this experiment), of PMMA to a lower temperature, as the $\mathrm{PVF}_{2}$ content increases. This temperature apparently corresponds to the $T_{\mathrm{g}}$ of the amorphous mixture, which we denote as $T_{\mathrm{g}}^{\mathrm{b}}$. For the MQ 50/50 blend, small peaks appear in both the $\log E^{\prime}$ and $\log E^{\prime \prime}$ curves immediately after the main glass transition at $T_{\mathrm{g}}^{\mathrm{b}}$. These small peaks are evidently due to the crystallization and remelting of $\mathrm{PVF}_{2}$ crystals from the amorphous blend, such as were seen in the DSC thermograms (cf. Figure 1). On the other hand, for the latter series the temperature, at which $\log E^{\prime}$ sharply decreases and $\log E^{\prime \prime}$ exhibits a peak, no longer changes with $\mathrm{PVF}_{2}$ content but remains at about $45^{\circ} \mathrm{C}$, which corresponds to the $T_{\mathrm{g}} \mathrm{b}$ of the MQ $(60 / 40)$ blend. Furthermore, the height of (or the area under) the $\log E^{\prime \prime}$ peak at about $45^{\circ} \mathrm{C}$ decreases, while a new peak appears at about $-40^{\circ} \mathrm{C}$ and becomes sharper, as the $\mathrm{PVF}_{2}$ content is increased above $\phi_{\mathrm{w}} \cong 0.6$. The low temperature dispersion corresponds roughly to the $T_{\mathrm{g}}^{\mathrm{PVF}_{2}}$ of pure $\mathrm{PVF}_{2}$. It should be noted that the area under the new peak appears to remain unchanged even with further increase in the $\mathrm{PVF}_{2}$ content. This result implies that the increase in the $\mathrm{PVF}_{2}$ content above $\phi_{\mathrm{w}} \cong 0.6$ contributes mainly to the increase in the crystalline regions but not much to that in the amorphous phase ( $c f$. Figure 2). In Figure 6 we also notice two other transitions at about $-80^{\circ} \mathrm{C}$ and $150^{\circ} \mathrm{C}$. Although the nature of such transitions is not clear at the moment, the former might be related to a secondary transition of the polymers, and the latter to the crystalline relaxation of $\mathrm{PVF}_{2}$.

In Figure 7 these $T_{\mathrm{g}}$ values are plotted against the $\mathrm{PVF}_{2}$ content, $\phi_{\mathrm{w}}$. The $T_{\mathrm{g}}^{\mathrm{b}}$ data for the amorphous mixture with $\phi_{\mathrm{w}} \lesssim 0.6$ closely fit the Gordon-Taylor equation proposed for compatible blends and

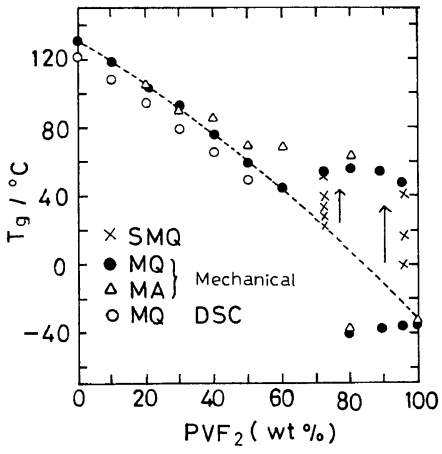

Figure 7. Dependence of glass-transition temperatures, $T_{\mathrm{g}}$, on the $\mathrm{PVF}_{2}$ content, $\phi_{\mathrm{w}}$, determined by DSC and dynamic mechanical experiments for melt-mixed and solution-mixed blends. Dashed curve represents the dependence predicted by the Gordon-Taylor equation. Arrows indicate the direction of increasing meltannealing time, $t$, for $\mathrm{SM}(t \mathrm{~min}) \mathrm{Q}$ blends. ( $c f$. Figures 8 and 9).

copolymers: ${ }^{12}$

$$
\left(T_{\mathrm{g}}^{\mathrm{PMMA}}-T_{\mathrm{g}}^{\mathrm{b}}\right)\left(1-\phi_{\mathrm{w}}\right)+k\left(T_{\mathrm{g}}^{\mathrm{PVF}_{2}}-T_{\mathrm{g}}^{\mathrm{b}}\right) \phi_{\mathrm{w}}=0
$$

where $k$ is $\Delta \alpha_{\mathrm{PVF}_{2}} / \Delta \alpha_{\mathrm{PMMA}}$ and $\Delta \alpha$ 's are the difference between the thermal expansion coefficients below and above the $T_{\mathrm{g}}$ 's of the homopolymers. For example, plots of $T_{\mathrm{g}}^{\mathrm{b}}$ versus $\left(T_{\mathrm{g}}^{\text {PMMA }}-T_{\mathrm{g}}^{\mathrm{b}}\right)\left(1-\phi_{\mathrm{w}}\right) /$ $\phi_{\mathrm{w}}$ give a straight line, which gives $k=1.35$ from the slope and $T_{\mathrm{g}}^{\mathrm{PVF}_{2}}=-35^{\circ} \mathrm{C}$ from the intercept. Similar plots of the DSC data (with $T_{\mathrm{g}}^{\mathrm{PMMA}}=120^{\circ} \mathrm{C}$ ) gave $k=1.35$ and $T_{\mathrm{g}}^{\mathrm{PVF}_{2}}=-50^{\circ} \mathrm{C}$. These values are in reasonably good agreement with literature values. ${ }^{1,3,13,14}$ Using these values, we recalculated and plotted the $T_{\mathrm{g}}^{\mathrm{b}}$ according to the Gordon-Taylor equation. The result is shown in Figure 7 by a dashed curve. The MQ blends with $\phi_{\mathrm{w}}$ below 0.6 and the MA blends with $\phi_{\mathrm{w}}$ below 0.5 possess only one $T_{\mathrm{g}} \mathrm{b}$ for each, and hence presumably a single amorphous blend phase, while the MA blends with $\phi_{\mathrm{w}}$ above these critical values possess two glass transitions for each phase. The $T_{\mathrm{g}}$ at higher temperature corresponds to the $T_{\mathrm{g}}$ of the amorphous blend with the critical composition and the $T_{\mathrm{g}}$ at lower temperature to the $T_{\mathrm{g}}$ of pure $\mathrm{PVF}_{2}$.

\section{Behavior of Solution Mixed Blends}

Figure 8 shows plots of $\log E^{\prime}$ and $\log E^{\prime \prime}$ versus temperature for an $\mathrm{S}$ blend and an SM (10 $\mathrm{min}) \mathrm{Q}$ blend with $72 / 28$ composition. The as-cast (S) blend 


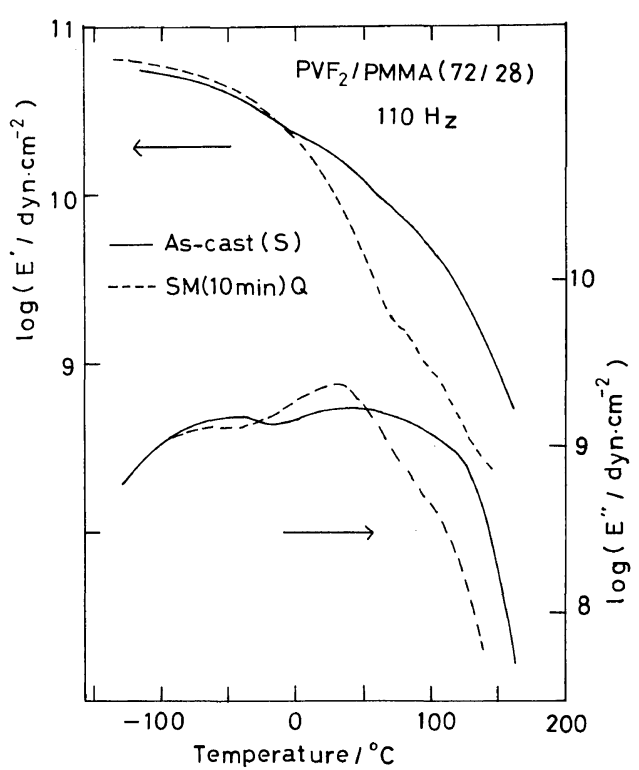

Figure 8. Temperature dependence of dynamic storage, $E^{\prime}$, and loss, $E^{\prime \prime}$, moduli at $110 \mathrm{~Hz}$ for a solventcast (S) and an SM (10 min) Q (72/28) blends.

temperature peaks. The thermograms were not normalized, and therefore are incapable of an absolute comparison.

exhibits a slow decrease in $\log E^{\prime}$ and two broad peaks in $\log E^{\prime \prime}$. A microscopic observation under polarized light on this blend revealed the presence of many small spherulites. The SM $(10 \mathrm{~min}) \mathrm{Q}$ blend exhibits at about $27^{\circ} \mathrm{C}$ a glass transition, which still differs significantly from the $T_{\mathrm{g}}^{\mathrm{b}}\left(\simeq 55^{\circ} \mathrm{C}\right)$ for the corresponding MQ (72/28) blend (cf. Figure 6). Figure 9 shows similar plots for the SM $(t \min )$ Q $(72 / 28)$ blends with various melt-annealing time $t$. For comparison, the data for the MQ (72/28) blend in the $T_{\mathrm{g}}^{\mathrm{b}}$ region are shown in the same figure. Apparently the temperature dispersion curve for the SM $(t \min ) \mathrm{Q}$ blends gradually shifts to that of the MQ blend. After 3200 minutes of melt-annealing, the two curves virtually coincide. Similar behavior was observed for a series of SM $(t \mathrm{~min}) \mathrm{Q}(95 / 5)$ blends. The SM $(10 \mathrm{~min}) \mathrm{Q}$ blend exhibited a sharp peak at the $T_{\mathrm{g}}^{\mathrm{PVF}_{2}}$ and a broad shoulder at about $20^{\circ} \mathrm{C}$, which corresponds to a $T_{\mathrm{g}}^{\mathrm{b}}$ of an amorphous blend with high $\mathrm{PVF}_{2}$ content. For this system, too, the temperature dispersion curve gradually shifted to that of the MQ blend, as the melt-annealing time $t$ increased. After 3400 minutes, the two curves nearly coincided with each other.

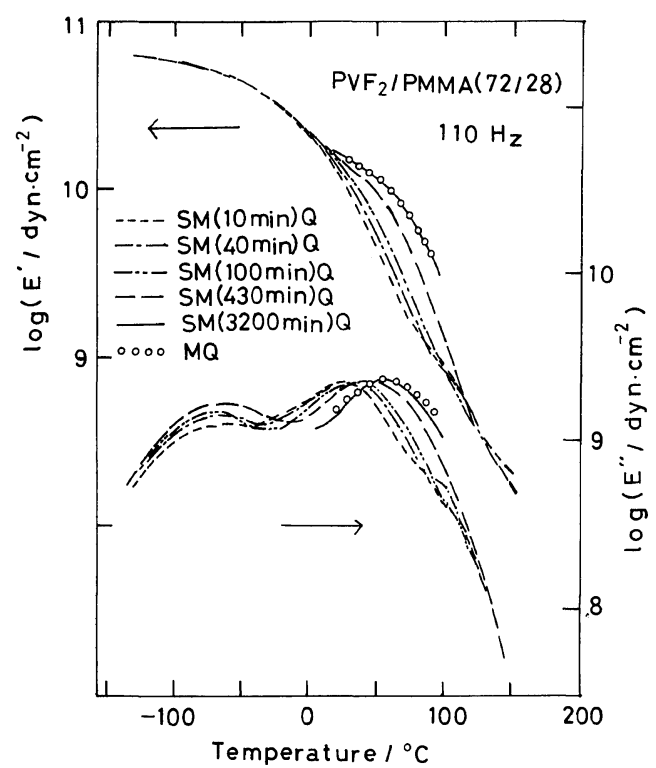

Figure 9. Variation with melt-annealing time, $t$, at $200^{\circ} \mathrm{C}$ of temperature dependence of dynamic storage, $E^{\prime}$, and loss, $E^{\prime \prime}$, moduli at $110 \mathrm{~Hz}$ for an SM $(t \min ) \mathrm{Q}$ $(72: 28)$ blend. Circles are the data for an MQ $(72: 28)$ blend covering the glass transition region.

For comparison, in Figure 7 we plotted the values of $T_{\mathrm{g}}^{\mathrm{b}}$ for the SM $(t \mathrm{~min}) \mathrm{Q}(72 / 28)$ and $(95 / 5)$ blends. Apparently, by prolonged melt-annealing at $200^{\circ} \mathrm{C}$ of the SMQ blends, the $T_{\mathrm{g}}^{\mathrm{b}}$ of the SMQ blends approach the $T_{\mathrm{g}}^{\mathrm{b}}$ of the MQ blends. This behavior probably explains the reason for the discrepancy found between the $T_{\mathrm{g}}^{\mathrm{b}}$ versus $\phi_{\mathrm{w}}$ relations for melt-mixed blends of Paul et al. ${ }^{2}$ and for solution-mixed blends of Nishi and Wang. ${ }^{3}$

The results in this and preceding sections suggest that the solution-mixed and melt-mixed blends with $\phi_{\mathrm{w}}$ above 0.6 may take on different morphologies. In the former, the two components are more thoroughly mixed with each other. However, when the $\mathrm{S}$ blend is kept in the molten state at $200^{\circ} \mathrm{C}$, phase separation takes place and the morphology gradually approaches the equilibrium state in which a mixture with $\phi_{\mathrm{w}} \cong 0.6$ and a nearly pure $\mathrm{PVF}_{2}$ melt are in the equilibrium. The LCST for this particular system might be about as low as or below $200^{\circ} \mathrm{C}$.

Effects of Molecular Weights of PMMA

Table II demonstrates the effects of the molecular 
Table II. Dependence of $T_{\mathrm{g}}$ and $T_{\mathrm{m}}$ on the molecular weight of PMMA in melt-quenched blends with $\mathrm{PVF}_{2} / \mathrm{PMMA}$ (50/50) and (80/20) compositions

\begin{tabular}{|c|c|c|c|c|}
\hline \multirow[t]{2}{*}{ Sample } & \multirow{2}{*}{$\begin{array}{c}T_{\mathrm{g}} /{ }^{\circ} \mathrm{C} \\
\text { (from } \mathrm{E}^{\prime \prime} \text { ) }\end{array}$} & \multirow{2}{*}{$\begin{array}{c}T_{\mathrm{g}} /{ }^{\circ} \mathrm{C} \\
\text { (from DSC) }\end{array}$} & $\begin{array}{l}\text { Crystallinity } \\
\text { in } \mathrm{PVF}_{2}\end{array}$ & \multirow[t]{2}{*}{$T_{\mathrm{m}} /{ }^{\circ} \mathrm{C}$} \\
\hline & & & $\%$ & \\
\hline \multicolumn{5}{|l|}{ (50/50 by weight) } \\
\hline $\mathrm{PVF}_{2} / \mathrm{PMMA} \mathrm{I}$ & 58 & 49 & 0 & $(160)^{\mathrm{a}}$ \\
\hline $\mathrm{PVF}_{2} / \mathrm{PMMA} \mathrm{II}$ & 60 & 50 & 0 & $(159)^{a}$ \\
\hline $\mathrm{PVF}_{2} / \mathrm{PMMA}$ III & 61 & 50 & 0 & $(158)^{\mathrm{a}}$ \\
\hline $\begin{array}{l}\text { (80/20 by weight) } \\
\mathrm{PVF}_{2} / \text { PMMA I }\end{array}$ & $\left\{\begin{array}{r}58 \\
-40\end{array}\right.$ & Not detectable & 62 & $\left\{\begin{array}{l}172 \\
161\end{array}\right.$ \\
\hline $\mathrm{PVF}_{2} / \mathrm{PMMA} \mathrm{II}$ & $\left\{\begin{array}{r}56 \\
-40\end{array}\right.$ & Not detectable & 60 & $\left\{\begin{array}{l}170 \\
160\end{array}\right.$ \\
\hline $\mathrm{PVF}_{2} / \mathrm{PMMA}$ III & 56 & Not detectable & 35 & 160 \\
\hline
\end{tabular}

${ }^{\text {a }} \mathrm{PVF}_{2}$ crystals develop during the heating process (rate, $10^{\circ} \mathrm{C} \mathrm{min}^{-1}$ ) in DSC experiments.

weight of the PMMA component on the thermal and viscoelastic behavior of the blends. In the table, the $T_{\mathrm{g}}, T_{\mathrm{m}}$ and the degree of crystallinity from DSC, and the $T_{\mathrm{g}}$ from dynamic mechanical experiments are compared for the MQ (50/50) and (80/20) blends in which the $\mathrm{PVF}_{2}$ is mixed with three PMMA samples. For the three MQ (50/50) blends, virtually no molecular-weight effects are found. For the MQ (80/20) blends, however, those containing PMMA I and II exhibit two $T_{\mathrm{g}}$ 's and two $T_{\mathrm{m}}$ 's, while the one containing PMMA III exhibits only one $T_{\mathrm{g}}$ and one $T_{\mathrm{m}}$. This imply that in the $\mathrm{PVF}_{2} / \mathrm{PMMA}$ III (80/20) MQ blends, the two components are still mixed in the melt and the phase separation does not fully proceed.

\section{DISCUSSION}

The thermal and viscoelastic behavior of $\mathrm{PVF}_{2} /$ PMMA II melt-mixed blends may be summarized as follows. For the blends with $\phi_{\mathrm{w}}<0.4$, the two components are uniformly mixed in the melt (at $200^{\circ} \mathrm{C}$ ). No crystallization may take place either by quenching from the melt or by subsequent annealing of the MQ blend at a temperature above its glass transition. Only one mixed amorphous phase exists in the blends. The glass-transition temperature obeys the Gordon-Taylor equation, and hence we denote it as $T_{\mathrm{g}}^{\mathrm{b}}$. For the blends with $0.4<\phi_{\mathrm{w}}<0.5$, the two components are miscible in the melt as well as in the quenched solid exhibiting only one $T_{\mathrm{g}}$ b. However, annealing of the quenched solid at a temperature above $T_{\mathrm{g}}^{\mathrm{b}}$ results in the formation of $\mathrm{PVF}_{2}$ crystals having one $T_{\mathrm{m}}$ that is subject to melting-point depression as described by Nishi and Wang. ${ }^{3}$ We tentatively denote these crystals as " $\beta$ crystallites," meaning those crystals which have grown out of the "blends." The $T_{\mathrm{m}}$ of the " $\beta$ crystallites" drops considerably with a decrease in the $\mathrm{PVF}_{2}$ content, suggesting that the " $\beta$-crystallites" are imperfect and contain an amorphous mixture entrapped between the crystalline lamellae.

For the blends with $\phi_{\mathrm{w}} \cong 0.6$, the two components are barely mixed with each other in the melt and in the quenched solid. The $\phi_{\mathrm{w}}$ is sufficiently large so that the crystallization of $\mathrm{PVF}_{2}$ can proceed, yielding " $\beta$-crystallites," during the rapid reheating process in the DSC experiment. Possibly, phase separation on a microscopic scale might have taken place even in the melt. The $\mathrm{PVF}_{2}$ microdomains might act as nuclei for rapid crystallization during the DSC experiment.

When $\phi_{\mathrm{w}}$ is further increased to, say, 0.8 , phase separation further proceeds in the melt, and a blend phase with $\phi_{\mathrm{w}} \cong 0.6$ and a nearly pure $\mathrm{PVF}_{2}$ melt might result. The quenching of such a melt yields a multiphase system consisting presumably of a mixed amorphous phase with $\phi_{\mathrm{w}} \cong 0.6$, a " $\beta$-crystalline 


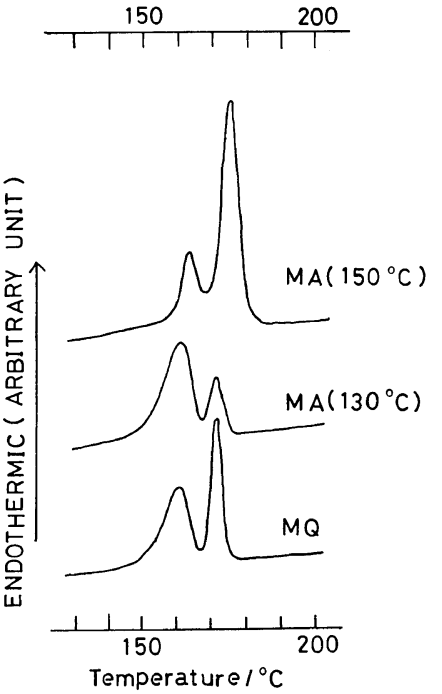

Figure 10. DSC thermograms for $\mathrm{PVF}_{2}$ melting regions of $\mathrm{PVF}_{2} / \mathrm{PMMA}$ II $(80 / 20) \mathrm{MA}\left(150^{\circ} \mathrm{C}\right), \mathrm{MA}$ $\left(130^{\circ} \mathrm{C}\right)$, and $\mathrm{MQ}$ blends, indicating the effect of the annealing temperature, $T_{\mathrm{c}}$, on the low and high temperature peaks. The thermograms were not normalized, and therefore are incapable of an absolute comparison.

phase" grown out of the mixed phase, and a nearly pure semicrystalline $\mathrm{PVF}_{2}$ phase. The semicrystalline phase is, more strictly speaking, composed of an amorphous $\mathrm{PVF}_{2}$ phase and a form II $\mathrm{PVF}_{2}$ crystalline phase. Thus the MQ $(80 / 20)$ blend exhibits two $T_{\mathrm{g}}$ 's and two $T_{\mathrm{m}}$ 's. The $T_{\mathrm{g}}$ at the higher temperature is $T_{\mathrm{g}} \mathrm{b}$ for the mixture with $\phi_{\mathrm{w}} \cong 0.6$ and that at the lower temperature is $T_{\mathrm{g}}^{\mathrm{PVF}_{2}}$. On the other hand, the $T_{\mathrm{m}}$ at the lower temperature is that for the " $\beta$-crystallites" and that at the high temperarure is for the form II $\mathrm{PVF}_{2}$ crystallites. Annealing of the MQ $(80 / 20)$ blend results in the development of the crystalline regions. However, the effect of the annealing temperature, $T_{\mathrm{c}}$, is quite interesting, as demonstrated in Figure 10. Since the chromatograms are not normalized, a direct comparison of the absolute magnitudes of the components is not possible. However, the results clearly indicates that annealing at $130^{\circ} \mathrm{C}$, being close to $T_{\mathrm{g}}^{\mathrm{PMMA}}$, reduces form II crystallites but develops " $\beta$-crystallites" considerably. On the other hand, an annealing at $150^{\circ} \mathrm{C}$ does the reverse.

We have attempted to elucidate the crystalline structures of these crystallites by a wide-angle X-ray diffraction method. However, so far no success has been achieved, because the degree of crystallinity relative to the whole blend specimen is too low and the structures themselves are too imperfect to yield clear diffraction data.

For melt-mixed MQ and MA blends with $\phi_{\mathrm{w}}=0.95$, nearly pure $\mathrm{PVF}_{2}$ domains are predominantly large in comparison with mixed domains. Thus, we observe only one $T_{\mathrm{g}}^{\mathrm{PV}_{2}}$ and only one $T_{\mathrm{m}}$ corresponding to form II crystallites, and the contributions from the blend phase are not clear.

For solution mixed as-cast (S) blends that have never been heated to a high temperature above the possible LCST around $200^{\circ} \mathrm{C}$ for a sufficiently long period of time, the two components are uniformly mixed and the blend exhibits only one $T_{\mathrm{g}} \mathrm{b}$ and one $T_{\mathrm{m}}$ (if $\phi_{\mathrm{w}}>0.5$ ). $\mathrm{PVF}_{2}$ crystallites, which are presumably what we have denoted as " $\beta$-crystallites," develop during the DSC experiment or even by quenching provided $\phi_{\mathrm{w}}>0.7 .^{3}$ For such blends the degree of crystallinity is usually quite low and the $T_{\mathrm{m}}$ drops considerably with an decrease in $\phi_{\mathrm{w}} \cdot{ }^{3}$ In this sense our present results on the multiphase behavior of the melt-mixed blends with high $\phi_{\mathrm{w}}$ $(\gtrsim 0.7)$ may not contradict previously reported results $^{1-3}$ of others, notably those of Nishi and Wang. ${ }^{3}$ Whatever contradictions there may be are apparently due to differences in temperature and the period of heat treatment of the blends. The LCST of this system appears to be much lower than that suggested earlier by Paul et al. ${ }^{6}$ This being the case, how has such a multiphase morphology came about? Previously, for compatible blends of meltmixed amorphous polymer/semicrystalline polymer systems, Stein et al. ${ }^{15,16}$ demonstrated from smallangle X-ray and light-scattering studies that in a certain system such as poly( $\varepsilon$-caprolactone)poly(vinyl chloride) (PCL/PVC) blends, the amorphous component is entrapped in the interlamellar region as an amorphous phase, while in another system such as isotactic polystyrene-atactic polystyrene (it-PS/at-PS) blends, a segregation of the atactic component occurs during crystallization within the growing spherulite, forming interspherulitic mixed amorphous domains.

This kind of kinetic effect during crystallization might be responsible for the effect of the annealing temperature, $T_{\mathfrak{c}}$, on the behavior of the MQ (80/20) blend shown in Figure 10. That is, during annealing at $150^{\circ} \mathrm{C}$, the PMMA component is segregated from 
the interlamellar region to the interspherulitic region, while during the annealing at $130^{\circ} \mathrm{C}$ the PMMA component is hardly mobile but the amorphous $\mathrm{PVF}_{2}$ component tends to mix with the entrapped PMMA component.

However, it is rather unlikely that this kind of the kinetic effect during crystallization is responsible for the multiphase behavior and the formation of the two different crystallites in the MQ (72/28) and $(80 / 20)$ blends. As was evident from the behavior of SMQ blends, a few hours of melt-annealing were necessary for an SMQ blend to approach the behavior of an MQ blend. That is, the rate constant for this process is of the order of hours, and it is impossible for this process to be completed within a matter of seconds during the quenching process. A liquid-liquid phase separation must take place in the molten blend before a solid-liquid phase separation takes place during crystallization by quenching from the melt. In which case, another kind of kinetic process must be effective in such a liquid-liquid phase separation process. The 15 times repetition of the melting-quenching process is enough for the $\mathrm{PVF}_{2} / \mathrm{PMMA}$ II MQ blends to reach an equilibrium or a quasiequilibrium state. However, the same procedure might not be sufficient for $\mathrm{PVF}_{2} /$ PMMA III $(80 / 20)$ to reach equilibrium. This explains the peculiar dependence of the phase-separation behavior of the $\mathrm{PVF}_{2} / \mathrm{PMMA}$ blends on the molecular weight of the PMMA component, such as shown in Table II. The $\mathrm{PVF}_{2} / \mathrm{PMMA}$ III (80/20) blend must have a lower cloud point than either the $\mathrm{PVF}_{2} / \mathrm{PMMA} \mathrm{I}$ or $\mathrm{PVF}_{2} / \mathrm{PMMA}$ II blends. Nevertheless, the former exhibited no evidence of a liquid-liquid phase separation but only one $T_{\mathrm{g}}^{\mathrm{b}}$ and one $T_{\mathrm{m}}$ for " $\beta$-crystallites." In other words, the former shows the typical two-phase behavior of a compatible semicrystalline polymer blend, in which. only a solid-liquid phase separation takes place. On the other hand, the latter two blends show the fourphase behavior of an incompatible or a semicompatible, semicrystalline polymer blend, in which both a liquid-liquid phase separation in the melt and a solid-liquid phase separation may take place during the quenching process. Here we must make one more comment on the molecular-weight dependence of the pahse-separation behavior of this system. For the molecular-weight dependence, an effect of the $\mathrm{PVF}_{2}$ domain size rather than the kinetic effect might be responsible. A melt, containing PMMA of a larger molecular weight, might have the mixed domains of a larger size and hence the $\mathrm{PVF}_{2}$ domains of a smaller size which might yield only " $\beta$-crystallites" when quenched from the melt.

Acknowledgement. We wish to thank $\mathrm{Mr}$. Shinsaku Uemura for his valuable advice on carrying out these experiments. This work was supported in part by the Ministry of Education, Science, and Culture under a Grant B 347081 to TK during 1976-1977.

\section{REFERENCES}

1. J. S. Noland, N. N.-C. Hsu, R. Saxon, and J. M. Schmitt, Adv. Chem. Ser., No. 99, 15 (1971).

2. D. R. Paul and J. O. Altamirano, Polym. Prepr., Am. Chem. Soc., Div. Polym. Chem., 15, 409 (1974).

3. T. Nishi and T. T. Wang, Macromolecules, 8, 909 (1975).

4. G. D. Patterson, T. Nishi, and T. T. Wang, Macromolecules, 9, 603 (1976).

5. D. J. Hourston and I. D. Hughes, Polymer, 18, 1175 (1977).

6. R. E. Bernstein, C. A. Cruz, D. R. Paul, and J. W. Barlow, Macromolecules, 10, 681 (1977).

7. H. Lee, R. E. Salomon, and M. M. Labes, Macromolecules, 11, 171 (1978).

8. D. C. Douglass and V. J. McBrierty, Macromolecules, 11, 766 (1978).

9. T. Nishi, Kobunshi, 27, 483 (1977); J. Macromol. Sci., Phys., B17 (1980) in press.

10. Y. Hirata, MS dissertation, Department of Macromolecular Science, Osaka University, 1979; Y. Hirata, S. Uemura, and T. Kotaka, Rep. Prog. Polym. Phys., Jpn., 22, 177 (1979).

11. K. Nakagawa and Y. Ishida, J. Polym. Sci., Polym. Phys. Ed., 11, 2153 (1973); S. Osaki and Y. Ishida, $J$. Polym. Sci., Polym. Phys. Ed., 13, 1071 (1975).

12. M. Gordon and J. S. Taylor, J. Appl. Chem., 2, 493 (1952).

13. G. M. Martin, S. S. Rogers, and L. Mandelkern, J. Polym. Sci., 20, 579 (1956).

14. L. Mandelkern, G. M. Martin, and F. A. Quinn, Jr., J. Res. Natl. Bur. Stand., 58, 137 (1957).

15. See, for exmple, F. B. Khambatta, F. Warner, T. Russell, and R. S. Stein, J. Polym. Sci., Polym. Phys. Ed., 14, 1391 (1976); R. S. Stein and T. Russell, Proceedings of The US-Japan Joint Seminar on Multicomponent Polymers, Kyoto, December 17-22, 1978; J. Macromol. Sci., Phys., B17 No. 2-4 (1980). 